\title{
Tres poéticas para la memoria y la resistencia: Avelino Sala, Adolfo Manzano y Ánxel Nava
}

\author{
Leticia González Menéndez* \\ Universidad de Oviedo
}

\section{RESUMEN:}

La memoria es «un campo de fuegos cruzados y armas de poder» (Le Goff, 1991). A partir de esta idea, tomando en consideración la proliferación de los Memory Studies a lo largo de las últimas décadas, planteamos una reflexión que aborda las correspondencias y antagonismos entre la acción creativa y los procesos de la memoria. La particularidad de nuestra propuesta se basa en el análisis de las diferentes problemáticas y dispositivos desde tres voces indispensables en el ámbito artístico asturiano: Avelino Sala, Adolfo Manzano y Ánxel Nava. El objetivo es observar desde qué metodologías se han elaborado acciones plásticas que, no sólo han buscado preservar la memoria, sino que han tratado de conservar "el olvido" para dejar aflorar nuevas perspectivas críticas y resistentes.

\section{PALABRAS CLAVE:}

Memoria, olvido, identidad, acción creativa, resistencia

\section{ABSTRACT:}

Memory is "a crossfire and power weapons" (Le Goff, 1991). From this idea and, considering the proliferation of Memory Studies over the last decades, we propose a reflection that deals with the correspondences and antagonisms between creative action and memory processes. The peculiarity of our proposal is based on the analysis of different devices from three indispensable voices in the Asturian art world: Avelino Sala, Adolfo Manzano and Ánxel Nava. The aim is to observe from what sort of methodologies have plastic actions been developed that have not only sought to preserve the memory, but have tried to keep "forget" to let new critics and resistance arise.

\section{KEYWORDS:}

Memory, forgetfulness, identity, creative action, resistance

\footnotetext{
El presente artículo recoge algunos de los resultados de la investigación acometida al amparo del programa de ayudas "Severo Ochoa" para la Formación en Investigación y Docencia del Principado de Asturias, en colaboración con el proyecto de Innovación en Ciencia y Tecnología del Principado de Asturias, FICYT.
} 


\section{Introducción}

"¿De qué hay recuerdo?, ¿de quién es la memoria?»" Así da comienzo la primera parte del ensayo de Paul Ricoeur La memoria, la historia y el olvido, una brillante reflexión que termina con una cuestión determinante: ¿cómo es la memoria? Este interrogante surge ante la perplejidad que suscita, como nos recuerda el propio Ricoeur, "el exceso de memoria aquí, el exceso de olvido allá, por no hablar de la influencia de las conmemoraciones y de los abusos de la memorian². Al abogar por el cómo el autor buscaba reintroducir una "fenomenología del recuerdo"3 que potenciara la fuerza de la memoria como el objeto de una "búsqueda»" Consideramos esa fuerza como el punto de partida que nos permite examinar críticamente las diversas problemáticas que engloba, no sólo el conjunto historia-memoria, sino también el vínculo memoria-arte. Por ello, nuestro objetivo a lo largo de los apartados que siguen es observar las experiencias de tres artistas: Avelino Sala, Adolfo Manzano y Ánxel Nava. Entendemos que, desde diferentes posicionamientos, los creadores han revisado aspectos próximos a una contra-memoria que han activado, en mayor o menor medida, procesos de apertura a fin de "facer de les nueses alcordances fuercies remocicaes $\|^{5}$. De este modo, proponemos un primer punto en el que se desvelan las principales correspondencias y antagonismos en torno a los estudios sobre la memoria. Seguidamente, abordamos un análisis de las líneas de acción de los tres artistas y, por último, elaboramos una descripción de lo que contemplamos como una preocupación compartida sobre los procesos de deconstrucción, tanto del discurso artístico, como de la propia manera de concebir la conexión con un pasado -si queremos "común"- pero reelaborado desde ópticas críticas más próximas a la identificación afectiva o a la experiencia y el acontecimiento.

RICOEUR, Paul, La memoria, la historia y el olvido, Fondo de cultura Económica de Argentina, Buenos Aires, 2000.

Ibídem., p. 13.

Ibídem., p. 19-20.

Ibídem., p. 20.

FORU ARTE CIUDÁ, "34 artistes, 14 díes de revolución", en Catálogo de la exposición Ochobre 34 artistes, 14 dies de Revolución, Centro de Arte Casa Duró, Mieres, 2004.

\section{Entre el recuerdo y los marcos sociales de} la memoria

La especificidad de los estudios sobre la memoria se generalizó a lo largo de la década de 1980 a través del conocido como Memory Boom $^{6}$. A pesar de que la génesis de estos discursos no es ni mucho menos novedosa -baste recordar el pensamiento clásico y sus dialécticas sobre la memoria, la imaginación, el recuerdo o la representación ${ }^{7}-$, su verdadero auge estuvo alimentado por la supuesta condición amnésica de un periodo (posmoderno) que constantemente se veía amenazado por el olvido. Los usos instrumentales del complejo memoria-historia y su posterior transformación han sido los pilares básicos sobre los que se han asentado la mayor parte de las propuestas. Como resultado, se han potenciado nuevas miradas hacia el pasado entendidas como estrategias "de salvación" ${ }^{~}$. "El giro hacia la memoria -escribe Andreas Huyssen- recibe un impulso subliminal desde el deseo de anclarnos en un mundo caracterizado por una cada vez mayor inestabilidad del tiempo y la fracturación de las espacialidades que habitamos ${ }^{9}$. En otros términos, se ha tratado de

\footnotetext{
Numerosos autores han asociado la aparición del Memory Boom al incremento de los procesos de globalización a gran escala experimentados por las sociedades posfordistas. Otra de las razones ha sido el creciente interés por determinadas nociones (memoria, recuerdo, rememoración, identidad) desde las poder re-estructurar patrones sociales y, sobre todo, huir de la amnesia a la que, supuestamente, está sometida la esfera social contemporánea. Por otra parte, la preocupación por la memoria ha estado demarcada por la sucesión de hechos trágicos y violentos y los modos a través de los que han sido reconocidos, recordados y representados. Hecho que, por otro lado, ha marcado el devenir de la historia mundial (Holocausto, genocidio, guerra, etc.).

7 El propio Ricoeur se hace eco de las problemáticas sobre imaginación y memoria que habían sido cuestionadas por Platón y Aristóteles. El autor establece un balance conceptual que sugiere que, a pesar de que ambos conceptos invocan a "la ausencia", es necesario un tercer elemento temporal para comprender la imbricación de la memoria en tal compendio. Consecuentemente, Ricoeur aborda desde un plano ontológico la "fiabilidad" del recuerdo en contraste con las disposiciones imaginativas.

8 Cfr. ADORNO, Theodor, "La educación después de Auschwitz", en Consignas, Amorrortu, Buenos Aires, 1993 y BENJAMIN, Walter, "Sobre el concepto de historia", en Tesis sobre la historia y otros fragmentos, Ed. Contrahistorias, México, 2004.

9 HUYSSEN, Andreas, En busca del futuro perdido, Fon-
} do de Cultura Económica, México, 2002, p. 24. 
transformar la "grisalla y la pasividad dominantes ${ }^{10}$.

Ante tales consideraciones, se retomaban cuestiones clave como las planteadas por Henri Bergson en Materia y Memoria ${ }^{11}$. "Pensamos sólo con una parte pequeña de nuestro pasado aunque deseamos, queremos y actuamos con todo nuestro pasado" ${ }^{12}$. Esta cita ha permitido redescubrir las problemáticas de la memoria desde el concepto dual de la misma. Es decir, siguiendo a Bergson, existe una conexión latente entre una memoria-hábito que es reformulada de modo constante por otra memoria-recuer$d o^{13}$. De esta manera, "el recuerdo es contemporáneo de aquello de lo que uno se acuerda -como ha señalado Gilles Deleuze- que es al mismo tiempo que algo es presente y es pasado» ${ }^{14}$. En consecuencia, se entiende el recuerdo como un punto esencial -parte indispensable de la memoria para Bergson-, como flujo o fuerza activa que siempre está presente en el sujeto a través de una "coexistencia virtual»" intermitente y cambiante.

Sin embargo, pese al interés que ha suscitado la deconstrucción temporal planteada por Bergson, su defensa de la individualidad ha sido razón de ser de otras lecturas críticas especialmente relevantes. De este modo, Maurice Halbwachs amplió los márgenes del concepto poniendo en duda la dualidad bergsoniana en La memoria colectiva ${ }^{16}$. Se destaca que "cualquier recuerdo, aunque sea muy personal (...) existe en relación con un conjunto de nociones que nos dominan más que otras; con personas, grupos, lugares, fechas, palabras y formas de lenguaje, incluso con razonamientos e ideas, es decir, con la vida material y moral de

10 GUATTARI, Félix, Las tres ecologías, Pre-Textos, Valencia, 1996, p. 79.

11 BERGSON, Henri, Memoria y vida, Alianza, Madrid, 1977.

12 Ibídem., p. 48. «Sin duda, no pensamos más que con una pequeña parte de nuestro pasado; pero es con nuestro pasado todo entero, incluida nuestra curvatura de alma original, como deseamos, queremos, actuamos. Nuestro pasado se manifiesta por tanto integramente en nosotros por su impulso y en forma de tendencia, aunque sólo una débil parte se convierta en representación".

13 Cfr. BERGSON, Henri, Memoria y olvido, Alianza, Madrid, 1977.

14 DELEUZE, Gilles, Derrames entre el capitalismo y la esquizofrenia, Ed. Cactus, Buenos Aires, 2005, p. 250.

15 BERGSON, Henri, Memoria y vida...Op. Cit., p. 55.

16 HALBWACHS, Maurice, La memoria colectiva, Prensas Universitarias de Zaragoza, Zaragoza, 2004. las sociedades de las que hemos formado parte ${ }^{17}$. Todo ello, cómo especificó el autor, desde "flujos de pensamiento continuo (...) puesto que se retiene del pasado lo que aún está vivo o es capaz de vivir en la conciencia del grupo que la mantiene ${ }^{18}$. En otras palabras, Halbwachs puntualizó la relación entre conciencia y tiempo vivido para justificar cómo la memoria se construye -con toda su energía y relevancia- de forma colectiva. Es en el recuerdo donde se encuentra la potencia de la marca social y desde donde se matizan los marcos sociales de la memoria ${ }^{19}$.

\section{Dispositivos para la memoria y el olvido}

Los estudios sobre la memoria colectiva han hilvanado una amplia amalgama de investigaciones que, desde diferentes disciplinas, han observado cuestiones como la cohesión grupal o la identidad. Sin embargo, más allá de los argumentos defendidos por Halbwach ${ }^{20}$, conviene señalar que "there is thus no collective memory; there are collective conditions which make memory possible» ${ }^{21}$. Así, las "condiciones colectivas" que ha propuesto Reinhart Koselleck sugieren mantener la idea crítica del cómo -la misma con la que iniciábamos este estudio- con el objetivo de reparar en la configuración social de la memoria, sobre todo, comprendiendo que «el presente es visitado por el pasado y éste es moldeado, inventado, reinventado y reconstruido por el presentew ${ }^{22}$. Con todo ello, conviene también preservar algunas de las tesis de Michel

17 HALBWACHS, Maurice, Los marcos sociales de la memoria, Anthropos, Barcelona, 2004. p. 55.

18 Ibidem.

19 Ibidem., p. 10.

20 HALBWACHS, Maurice, "Fragmentos de la memoria colectiva”, en Revista de Cultura Psicológica, n 1, vol. 1, Facultad de Psicología, UNAM, México, 1992. "Lo que llama la atención es que en la memoria las similitudes pasan a primer plano. El grupo, cuando mira su pasado, siente que sigue siendo el mismo y toma conciencia de su identidad a través del tiempo. La historia no recupera los intervalos de tiempo en que aparentemente no pasa nada, en que la vida se limita a repetirse bajo formas poco diversas, sin alteración esencial, sin rupturas ni sobresaltos».

21 KOSELLECK, Reinhart, "Gibt es ein kollektives Gedächtnis?”, en Divinatio, n 19, vol. 2, 2004, p. 21 y VV. AA., The Ashgate Research Companin to Memory Studies, Siobhan Kattago (ed.), Ashgate, Surrey, 2015, p. 4.

22 ASSMANN, Jan, Moisés el Egipcio, Anaya, Madrid, 2003, p. 22. 
Foucault ${ }^{23}$ sobremanera aquellas que inspeccionan los modos a través de los que se introducen las prácticas discursivas ya que, desde las relaciones de saber-poder o regímenes de verdad ${ }^{24}$, se estipulan gran parte de las condiciones y/o dispositivos de la memoria. En decir, se señala aquello que debe ser "memorable" desde fuerzas como la enunciabilidad o la visibilidad.

Esta energía simbólica ha sido muchas veces aplicada mediante elementos de identificación (monumentos) que han impuesto "memorias oficiales" y, a su vez, han legitimado unas historias en pos de silenciar otras. Se hace evidente, por lo tanto, que desde la representación puede observarse la distancia entre dos conceptos siempre paralelos; así, "no hay que confundir historia con memoria ${ }^{25}$ aconsejaba Pierre Nora. La memoria debe comprenderse como algo "abierto a la dialéctica del recuerdo y de la amnesia, sensible a todas las transferencias, pantallas, censuras o proyecciones, afectivas y mágicas ${ }^{26}$. Ahora bien, siguiendo a José Luis Barrios, si desde la historia se da forma a las memorias, supuestamente sometiéndolas a análisis, a su vez la memoria debería descubrir los ángulos muertos y señalar los ocultamientos de la historia.

No obstante, estamos "tocados" por índices -conviene evocar la idea básica del devenir-imagen de la que trata Ricoeur en relación a la memoria ${ }^{27}$ - de un pasado que se aprende como colectivo en sus imágenes y representaciones y, por ello, en sus rememoraciones. "La imagen -apuntaba Walter Benjamin- es como aquello en donde lo que ha sido se une como un relámpago al ahora de la constelación $"^{28}$.

23 Considera la Historia como un discurso más que selecciona, justifica y conmemora. Esta perspectiva marca lo que Foucault entendió como una "insurrección del conocimiento subyugado". No obstante, la apertura e imbricación con el sujeto supuso un cambio en la historia que se transformó en arena de lucha, tal y como lo observó el teórico en La arqueología del saber, precisamente ante su deconstrucción en "historias" o "relatos" múltiples. Cfr. FOUCAULT, Michel, La arqueología del saber, Siglo XXI, Madrid, 1979.

24 Cfr. FOUCAULT, Michel, Microfísica del poder, Ed. La piqueta, Madrid, 1980.

25 CORRADINI, Luisa, "No hay que confundir memoria con historia”, en La Nación, 15 de marzo de 2006.

26 NORA, Pierre (dir.), Les Lieux de Mémoire 1, Gallimard, París, 1984, pp. 27-44.

27 Cfr. RICOEUR, Paul, La memoria, la historia y el olvido, Fondo de cultura Económica de Argentina, Buenos Aires, 2000.

28 BENJAMIN, Walter, El libro de los pasajes, Akal, Madrid, 2004, p. 464.
Podemos preguntarnos entonces: ¿la memoria se estructura desde el propio acontecimiento pasado, desde el sujeto o desde los dispositivos por medio de los cuales se establece como entidad compartida?29. ¿Existe entonces un exceso de memoria?, ¿qué ocurre con el olvido?

El poder de la relación compleja entre memoria e historia repliega al olvido a la posición del enemigo y ensalza los procesos de lo impertérrito, "del recuerdo de lo que se ha olvidado, un "olvido inolvidable", un pasado irrepresentable que asedia todo el presente como fantasma o espectro» ${ }^{30}$. Así, relegado al olvido, el exceso de memoria se comprendió como una condena a la angustia sin remedio, cuando a no a una locura $^{31}$. Por lo tanto, a tenor de las observaciones, es innegable destacar el carácter mutable y extensivo de las memorias, tan anchas como lo son sus usos políticos ${ }^{32}$. En definitiva, cabe preguntarse en consonancia con Huyssen, si la proliferación de la(s) memoria(s) -y los dispositivos que las controlan- puede desembocar en una estandarización $\mathrm{u}$ homogeneización aún más vacua y vacía: «¿qué sucedería si el boom de la memoria fuera inevitablemente acompañado por el boom del olvido? ${ }^{33}$.

29 El concepto puede analizarse a través de diferentes discursos y metodologías y, ante tal consideración, los análisis varían considerablemente. Por una parte, se podría diferenciar la memoria social de la comunicativa. Sin embargo, precisamente por el buen entendimiento que Robert Lechner hace de la obra de Henri Halbwach, el acercamiento más acertado podría resumirse en que "la memoria es una relación intersubjetiva elaborada en comunicación con otros y en un determinado entorno social. En consecuencia, solo existe en plural. La pluralidad de memorias conforma un campo de batalla en el que se lucha por el sentido del presente en orden a delimitar los materiales con los cuales construir el futuro (...) La construcción social de la memoria se inserta en un proceso mas general: la construcción del tiempo social».

30 LYOTARD, Jean-François, Heidegger y los judios, La Marca, Buenos Aires, 1995, pp. 36-37.

31 TODOROV, Tzvetan, Los abusos de la memoria, Paidós, Barcelona, 2000, p. 33.

32 HUYSSEN, Andreas, En busca del futuro perdido. Cultura y memoria en tiempos de globalización, Fondo de Cultura Económica, México, 2002, p. 22.

33 Ibídem., p. 22. A este respecto, el autor no duda en afirmar que: «la temporalidad contemporánea se produce, fundamentalmente, a través de la compleja interacción de fenómenos tales como los cambios tecnológicos, los medios de comunicación masivos, los nuevos patrones de consumo y movilidad global" y concreta "por mucho que nuestra preocupación por la memoria sea un deslizamiento de nuestro miedo al futuro y por más dudosa que nos pueda resultar hoy la proposición que afirma que podemos aprender la historia, la cultura de 


\section{Memoria(s) e identidades múltiples}

¿Qué papel tiene la memoria en la actualidad cuando lo simbólico ya no tiende a rememorarse sino que se produce constantemente? ${ }^{34}$. La respuesta del propio José Luis Brea sugiere no volver sobre la historia como eje central, sino más bien a la idea de generar energías simbólicas que no miren solamente hacia el pasado sino que se desarrollen en un constante devenir futuro, a la búsqueda de un nuevo conocimien$t^{35}$. La coherencia de la cuestión se traduce en las problemáticas asociadas a la velocidad abismal con la que actualmente surgen nuevas experiencias, imágenes $\mathrm{o}$, incluso, recuerdos. No cabe duda que el papel de la memoria ya no se basa en perpetuar una sola identidad sino que tiende a lo múltiple y a lo cambiante desde diferentes procesos maquínicos ${ }^{36}$. Por ello, la memoria se torna, hoy más que nunca, un arma de doble filo. Por un lado, se multiplica y extiende de una manera exponencial y, por otro, interfiriere en los desarrollos sociales suponiendo una transformación en la fase más endémica de la globalización; es decir, la memoria se muestra como un medio a través del cual lo local y lo concreto se entrecruzan y superponen a lo global de una manera continuada. La función de los dispositivos de la memoria está, consiguientemente, bipolarizada. Siguiendo a Brea, ya no existiría una sola memoria como un único proceso, sino interconexiones comunicacionales (memorias en red) activas a través de patrones de intercambio. Las nuevas formas de identidad ya nada tienen que ver con lo permanente. "Aquí los fantasmas tienen nombre y orgullo de época (...) pero, sobre todo, tienen nombre de comunidad, de esa comunidad sin destino fijo que atraviesa la historia como abandonada a su suerte incierta en ese filo, absuelta de viejas herencias y enfrentada al abismo de una incertidumbre siempre renovada $»^{37}$.

la memoria cumple una importante función en las actuales transformaciones de la experiencia temporal que ocurren como consecuencia del impacto de los nuevos medio sobre la percepción y la sensibilidad humana».

34 BREA, José Luis, Cultura RAM. Mutaciones de la cultura en la era de su distribución electrónica, Gedisa, Barcelona, 2007.

35 Ibídem., p. 5

36 Procesos dominados por los medios de comunicación, la publicidad o el marketing.

37 BREA, José Luis, Cultura RAM. Mutaciones de la cultura en la era de su distribución electrónica, Gedisa, Barcelona, 2007.
¿Cuál es el papel del arte en este contexto?. Consideramos que la práctica creativa debe ser productora de una nueva memoria, de contra-memoria, de criticidad cognitiva; debe generar espacio público, esfera pública y «adaptarse a una transformación genérica de la ontología del signo que hace que se transforme en profundidad nuestro sentido de lo igual en el mundo (...) hacia una nueva función orientada en cambio a la producción de diferencia, a la generación de novedad, a la invención de conceptos de sentido" ${ }^{38}$. Irremediablemente aparece la necesidad de recomponer las metodologías memorísticas a fin de buscar nuevas relaciones conceptuales que, ante la situación contemporánea, permitan desarrollar momentos de resistencia o crítica en pos de volver a una "búsqueda" que, ante todo, fomente un "pensar diferente de lo que se piensa y percibir diferente de lo que se ven ${ }^{39}$.

En consecuencia, lo que los artistas que vamos a introducir a continuación mantienen en común es una apuesta que exige un intercambio entre las disposiciones de una cultura que se supone común y los modos de señalar conflictos, problemáticas o preocupaciones con el objetivo de generar otros modelos de memoria, de recuerdo y de rememoración. En otros términos, siguiendo Félix Guattari, sus búsquedas se centran en promover «el conjunto de condiciones que vuelven posible instancias individuales y/o colectivas en posición de emerger como territorio existencial sui-referencial, en adyacencia o en relación de delimitación con una alteridad ella misma subjetiva (...) más próxima a la lógica de los afectos que a la de los conjuntos bien circunscritos ${ }^{40}$. En definitiva, potenciar lo que Iuri Lotman clasificó como «memoria creadora" en contra de la memoria "informativa»" para aspirar a una utopía de la proximidad que se base en una refundación más que en una reconstrucción ${ }^{42}$.

Ibidem.

39 MUCHAIL, Salma T., Foucault, simplemente, Ed. Loyola, São Paulo, 2004, p. 20.

40 GUATTARI, Félix, La ciudad subjetiva y post-mediática. La polis reinventada, Fundación Comunidad-Cali, Colombia, 2008, p. 61.

${ }^{41}$ LOTMAN, Iuri M., La semiosfera. Semiótica de la cultura y el texto, Cátedra, Madrid, 1996, pp. 157-161.

42 BOURRIAUD, Nicolas, Estética relacional, Ed. Adriana Hidalgo, Buenos Aires, 2008, p. 8. 
5. La piedra, la huella y la interferencia. Tres poéticas de la contramemoria

En el contexto artístico asturiano han aparecido, a lo largo de las últimas décadas, creadores y creadoras que podemos definir como "maestros y maestras de la sospecha" ${ }^{43}$. Todos ellos han sido, en mayor o menor medida, agitadores que han sabido colocar su idea de la memoria y la historia desde la mirada del que sabe donde mira y lo que mira. Tal como apuntó al respecto Ánxel Nava: "nuestro arte es el arte del acecho» ${ }^{44}$. Por otro lado, no podemos obviar las historias que rodean a los tres artistas que vamos a abordar, todas ellas relacionadas con el pasado más reciente de Asturias: "perda del patrimoniu, crisis industrial, estigmatización de la llingua y la cultura, el descréditu de los discursos identitarios n'esficies d'una falsa universalidá. La sociedá asturiana vive una fonda crisis identitaria. Les memories individual y artística espeyen esta situación $»^{45}$. Con ello, entendemos que las acciones creativas que a continuación describimos han tenido la intención de superponerse a las condiciones históricas y acercarse a otros métodos de carácter más genealógico o arqueológico. Todo ello, para buscar esa conexión clave que delimita una idea de "nosotros y nosotras", o lo que es lo mismo, "sentir que somos voces de una misma penuria» ${ }^{46}$.

En este sentido, la obra de Avelino Sala gira en torno a la deconstrucción de las huellas y la identidad. No en vano, ya en su primer proyecto destacable, Void Proyect (1998), se aludia a conceptos como el vacío, la soledad o la ausen$\mathrm{cia}^{47}$. Sin embargo, ha sido en iniciativas como Restlessness (2003) o Ícaro (2004) donde verdaderamente se ha revelado la puesta en marcha de un "imaginario nómada" y también de «una voluntad de dotar a la obra de una contra-mo-

43 Introducimos un guiño a la expresión con la Paul Ricoeur definía a una trilogía de pensadores elementales: Marx, Nietzsche y Freud. Cfr. RICOEUR, Paul, Freud: una interpretación de la cultura, Siglo XXI, Madrid, 2004.

44 FORU ARTE CIUDÁ, “34 artistes, 14 díes de revolución...Op. Cit.

45 Ibídem.

46 BORGES, Jorge Luis, Obras completas 1923-1972, Emecé, Buenos Aires, 1974, p. 62.

47 BARROSO, Julia y TIELVE, Natalia, El arte actual en Asturias. Un patrimonio en curso, Trea, Gijón, 2005, p. 308. numentalidad ${ }^{48}$. Resulta imprescindible este apunte de Fernando Castro ya que imbrica a la obra del artista con las dinámicas de la memoria y, sobre todo, con el cómo se da tal proceso de rememoración. Una de las metodologías plásticas consistía en la elaboración de figuras antropomorfas creadas con cinta adhesiva. Las estructuras trasparentes eran colocadas en espacios específicamente elegidos con una misión clara: generar interferencias o "desasosiego", pero también nuevos niveles de identificación en lugares industriales en desuso. Avelino Sala gestionaba así otros parámetros narrativos que deconstruían las características simbólicas de los espacios intervenidos; esto es, se creaban "paisajes de acontecimientos" $49 \mathrm{y}$, por ello, se removían las dimensiones memorísticas. «Esta producción artística -apunta Sala- cumple con un obligatorio ejercicio de reacción hacia ciertas prácticas artísticas que derivan en lo decorativo, anteponiendo una función del arte que se centra más en ser un reflejo de aquellas realidades, tanto actuales como pasadas, que el hombre pretende olvidar ${ }^{50}$. En definitiva, se trataba de "cuestionar desde una perspectiva crítica, el contexto social, geográfico y político en el que nos encontramos» ${ }^{51}$. Con ello, tal como lo describe Natalia Tielve, su análisis se basa en "la Asturias contemporánea castigada por la desindustrialización y la crisis (...) ilustra esa situación crítica, aunque manteniendo una puerta abierta a la esperanza, a la utopía (...) hace que lo post-humano imponga una lógica de lo antimonumental ${ }^{52}$. Así, una de las características esenciales de Sala es la reconstrucción de las ruinas a las que aporta una resignificación, atendiendo a las diatribas entre los espacios físicos, los espacios mentales y los espacios sociales. Como estrategia intenta buscar, siguiendo a Barthes, un nuevo lenguaje a

${ }_{48}$ CASTRO FLÓREZ, Fernando, "El imaginario nómada de Avelino Sala en el tiempo de la dislocación”, texto específicamente elaborado para el proyecto, [en línea]: disponible en la url: http://w3art.es/asala/index.htm

49 Cfr. VIRILIO, Paul, Un paisaje de acontecimientos, Paidós, Barcelona, 1998.

50 SALA, Avelino, “texto sobre Inquietud I (2002)", en Generación 2003, Premios y Becas de Arte Caja Madrid, La Casa Encendida, Madrid, 2003, p. 32.

51 SALA, Avelino, texto inédito sobre Inquietudes/Restlessness, 2003, [en línea]: disponible en url: http:// w3art.es/asala/index.htm

52 ÁLVAREZ, Soledad y TIELVE, Natalia, "Emergencias: el arte joven en Asturias. Semblanza de una trayectoria plural”, en ¿Qué arte? Discursos sin fronteras, Universidad de Oviedo, Oviedo, 2008. 
objeto de introducir otros héroes posibles, una nueva épica que se resitúe en una edad ficticia de héroes y culturas fuertes ${ }^{53}$.

En este sentido, la instalación Disparad sobre nosotros el enemigo está dentro (2008) ha sido un ejemplo paradigmático. Se trató de una intervención -a través de un neón o cartel luminoso ${ }^{54}$ - en el conjunto decimonónico del águila imperial que encabeza el teatro de la Universidad Laboral de Gijón. Bajo este símbolo ${ }^{55}$ Sala colocó una pantalla en la que podía leerse un mensaje claro tomado de Walter Benjamin: «La historia es objeto de una construcción cuyo lugar no está configurado por un tiempo homogéneo y vacío sino repleto de tiempo-ahora ${ }^{56}$. Se trató de plantear una nueva tarea de rememoración y aunar de manera contradictoria lo monumental y lo contradiscursivo, aportando otro concepto de "aura" que permitiera a los espectadores formar un discurso cuya interpretación quedaba liberada de los valores semióticos del águila y el edificio en sí mismos. "Avelino ha planteando -como apunta Fernando Castrouna intervención pública en la que, por medio de suplementos textuales, abre la posibilidad de un arte de la memoria (...) El artista no quiere fijar los documentos del pasado, sino al contrario, su intención es hablar de lo que nos pasa, esto es, confrontar lo que ha sido con la actualidad. "El arte muestra la política, la expone en el doble sentido del término -argumento de discurso y disposición de imágenes- se expone a ella constantemente" $n^{57}$.

Por otro lado, cuando James E. Young propuso el neologismo Counter-Monuments su objetivo era poner en duda los modelos de funcionamiento clásico del monumento y, a la vez, ampliar y cuestionar sus límites. La hipótesis que ha barajado el autor se ha centrado en la observación del carácter complejo y contradictorio de este tipo de arte situado en los espacios públicos. Se ha destacado que

53 Cfr. BARTHES, Roland, Mitologías, Siglo XXI, Madrid, 1999.

54 MERAYO, Paché, "Sala lleva la memoria histórica a la plaza”, en El Comercio, 7 de junio de 2008.

55 GEA, Juan Carlos, "Sala recicla simbólicamente el águila de la Laboral”, en La Nueva España, 12 de junio de 2008 y CERECEDA, Miguel, "Del impero romano a la hamburguesa", en El Cultural del $A B C, 14$ de junio de 2008.

56 BENJAMIN, Walter, "Tesis sobre la Filosofía de la Historia”, en Discursos interrumpidos I, Taurus, Madrid, 1982, p. 188.

57 Ibídem., p. 18

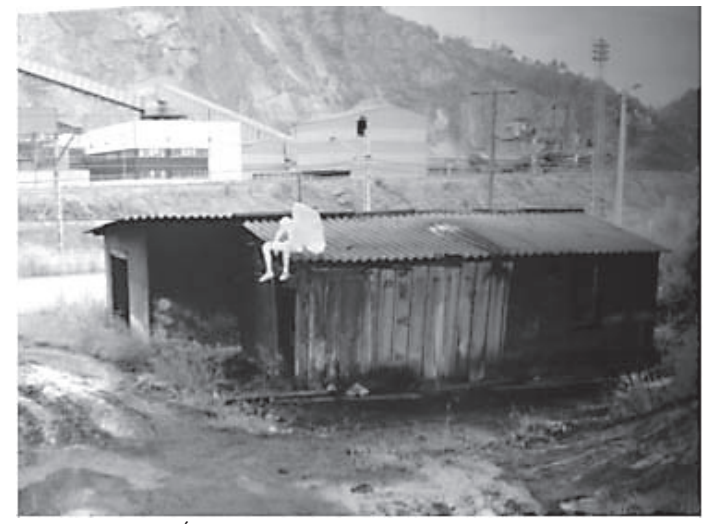

Fig. 1. Proyecto Ícaro, Avelino Sala, Instalación site-specific y fotografía, 2004. Fuente: Archivo personal de Avelino Sala.

en la mayoría de las ocasiones los monumentos van más allá de sus condiciones históricas para establecerse en un punto muerto y, como hemos visto, unilateral. De este modo, el teórico ha desarrollado una cuestión clave en la que se involucra la memoria: la neutralización del monumento impide la «calidad de la conciencia histórica pública $"^{58}$. En otros términos, "el monumento permanece inmune al tiempo y al cambio, una reliquia-testigo sobre una persona, un evento o una épocan ${ }^{59}$. Por lo tanto, la contestación a tales aspectos se ha de concentrar en el fomento de la no-conmemoración, de las historias no-oficiales o los testimonios de aquellos que no tuvieron derecho al "tener lugar"; esto es, reelaborar cuestiones estéticas que vuelvan la mirada a la contra-memoria o la memoria afectiva $^{60}$. Así, el contra-monumento atañe directamente a la acción de "recordar" y, en definitiva, se define como "la negación del espacio conmemorativo dolorosamente autoconsciente concebido para desafiar las premisas esenciales de su ser ${ }^{61}$.

Siguiendo estas consideraciones, el artista Adolfo Manzano siempre ha sido muy consecuente con la importancia que la práctica crea-

58 SIGEL, Paul, "Counter-Monuments - Criticising Traditional Monuments", [en línea]: disponible en url: http://www.goethe.de/kue/arc/dos/dos/zdk/en204638. $\mathrm{htm}$

59 YOUNG, James, At Memory's Edge: After-Images of the Holocaust in Contemporary Art and Architecture, Yale University Press, London, 2000, p. 196.

60 FOUCAULT, Michel, language, Counter-Memory, Practice: Selected Essays and Interviews, Cornell University Press, New York, 1977, p, 154.

61 YOUNG, James, "The Counter-monument: Memory against itself in Germany”, en Critical Inquiry, , n 2, vol. 18, invierno 1992, pp. 267-296. 

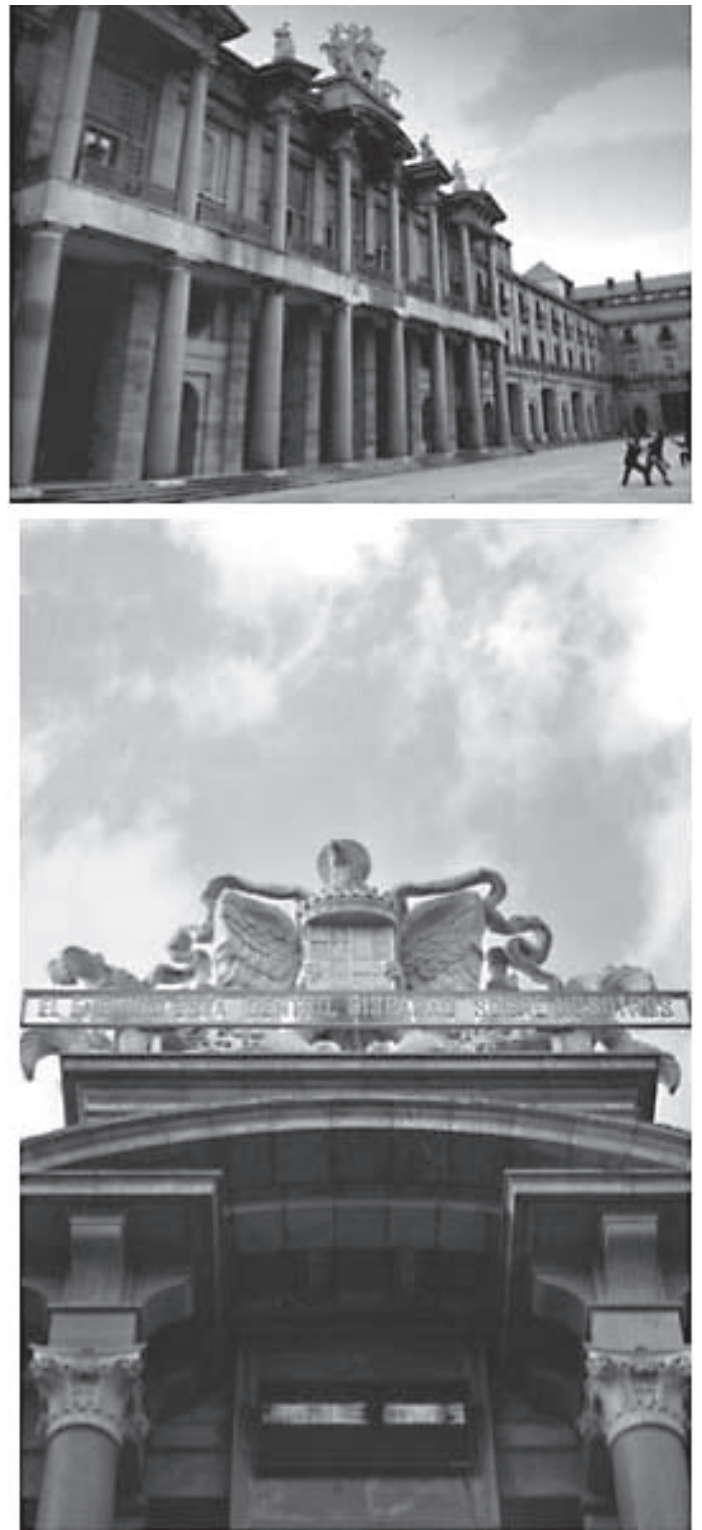

Fig. 2. En la parte superior: Derrocar el poder, video-acción, Gijón, Universidad Laboral, 2008. En la parte inferior: Disparad sobre nosotros el enemigo está dentro, Instalación site-specific, Gijón, LABoral Centro de Arte, 2008. Fuente: Archivo personal de Avelino Sala.

tiva tiene con respecto a los procesos de identificación del sujeto o, en otras palabras, con los modos de operar que activan las diferentes formas de subjetivación. Sus experiencias transitan a través del acontecimiento simbólico o desde su situación corporal $^{62}$, siempre comprendiendo que "existir en un espacio, ser un punto, un individuo en un espacio, significa diferir, ser diferente (...) ser distintivo y ser signi-

62 Ibidem., p. 390. ficativo" ${ }^{63}$. No obstante, mantiene muy presente la idea de generar agenciamientos colectivos que replanteen desde diferentes estrategias la composición de las memorias colectivas. Manzano recompone lo imaginario y lo simbólico pero a fin de "tocar" lo real desde (y por) el que concibe, comprende y siente.

Como ejemplo básico de su trayectoria cabe destacar El centinela de la memoria (1992) que situó en el monte Monsacro (Oviedo). El título de la obra hace referencia explícita a las políticas de la memoria y apunta a las disposiciones simbólicas y rituales que supone la representación de un altar en un espacio cargado de energía telúrica, creencia y ritualidad. Se hacía clara referencia a la memoria, "tresformando'l espaciu nun llugar sagráu. Ye evidente que ellí pasó (na remota infancia'l mundu) d'algo que cambió l'universu. Nun sabemos que foi pero eses ruines perfeutes son elexía y canción, fortuna y melandanza" ${ }^{64}$.

Las experiencias creativas de Manzano han propuesto líneas de fuga, pero a la vez, también otros mitos y rituales, quizá más personales. Sus propuestas embriagan al espectador invitándolo a la meditación, a retomar una espacialidad propia por medio del acto y la comprensión de formas y materiales con el objetivo de eliminar los límites espaciales y las demarcaciones; «meditación sobre los límites tanto propios como los que tienen que ver con los lugares" ${ }^{65}$. Canto a los dies fuxios (2001) situada en el Cervigón de la Providencia (Gijón) imbrica al espectador y «le incluye desde su experiencia más allá de cualquier atribución dogmática del sentido» ${ }^{66}$. Canto a los dies fuxios no deja de ser «un tiempo suspendido, ensoñación extrema y humanidad $n^{67}$. Aquí la escultura hace clara referencia a la condición activa del olvido. En palabras del artista: "La obra situada en Gijón pretende expresar un convencimiento según el cual son esos momentos que se van de nuestra memoria los que de verdad constituyen nuestra vida" ${ }^{68}$.

En una dinámica diferenciada, destacamos La piedra de la fortaleza será desierto (1999), una intervención llevada a cabo en la Plaza de

\footnotetext{
63 BOURDIEU, Pierre, Razones prácticas sobre la teoría de la acción, Anagrama, Barcelona, 1997, p. 21.

${ }^{64}$ BELLO, Xuan, "La cosmogonía d'Adolfo Manzano", en El Summun no 3, 2007, p. 6.

65 Ibídem.

${ }_{66}$ Ibidem.

67 Ibídem.

68 Conversaciones con Adolfo Manzano, abril de 2014.
} 
La Gesta de Oviedo. La ubicación de la instalación fue significativa ya que se dispuso frente a un elemento "público" - una lápida en conmemoración a la defensa de Oviedo por parte del bando nacional en la Guerra Civil española- instalada de modo permanente en la misma plaza de la capital asturiana. El artista creó un bloque de mármol blanco de las dimensiones exactas de la lápida. En una de las caras del cubo de mármol se proyectaba una luz roja permanentemente encendida que era alimentada por un acumulador solar. Lo relevante de esta pieza era su marcado carácter antimonumental. Manzano se esfuerza por señalar y demarcar el conflicto, el problema de la conmemoración y, sobre todo, a aquellos que no tuvieron acceso ni al espacio ni a la opinión pública. La instalación representa una contradicción y una ensoñación que, frente a frente a la verdad oficial, presenta otro modo imaginario de restitución, de resistencia, de confrontación con la historia impuesta; "la gesta no cantada", una «memoria sin recuerdo" ${ }^{69}$.

Del mismo modo, produce $A$ los héroes que fuimos (2007). Para esta pieza de arte público el artista pensó en el sentido que el arte adquiere al enfatizar su condición como medio expreso de manifestación de poder y su vocación de perennidad. Comprendió Manzano cómo la escultura monumental reúne en su repertorio todos los ingredientes de la visualización ineludible de la autoridad, sus medios y agentes. En busca de una nueva conexión, vincula las disposiciones clásicas del monumento escultórico con el mundo de la infancia. En líneas generales se atendía y señalaba de manera irónica cómo, de un modo u otro, los esquemas tradicionales de monumentalización siguen activos. Manzano jugaba con la idea "plaza pública" o "monumento" pero siendo muy consciente de los procesos democráticos que deben sobresalir en tales espacialidades públicas. De ahí que tome un caballo balancín sobredimensionado como eje de actuación ya que termina por comprenderlo como un auténtico "monumento público". Así, cuando a Adolfo Manzano se le pregunta por el espacio público y su íntima relación con el arte, la identidad y la memoria, este responde de manera concisa que: "la escultura pública sigue siendo víctima del concepto con que se

69 SUÁREZ, Rubén, "Por el camino de los escultores", en Catálogo de Confluencias 2002. La escultura asturiana hoy, Universidad de Oviedo, Oviedo, 2002, pp. 40-53. la tuvo durante siglos, el mero ornamento de la vía pública» ${ }^{70}$.

Desde otro punto de vista, el término "heterotopía"71 se relaciona con la idea de lo múltiple y lo fragmentario. Espacios mutables cuya memoria común ha de ser reelaborada a partir de un devenir arqueológico, desde nuestras propias marcas y huellas. El Manifiestu de la Arqueoloxía del Suañu recoge estas cuestiones y las principales líneas de trabajo creativo del artista, escritor y agitador cultural Ánxel Nava -Bardu errante, agrimensor y arqueólogo del sueño y/o el guardián de la memoria-. El artista ha tenido un objetivo claro a lo largo de su trayectoria: defender la dignidad del arte, sobre todo, a través de prácticas que se vinculen con la memoria, la tierra y la identidad. Así en palabras del creador: "Llende del espaciu-tiempu independiente del güeyu y puntu de mira (...) l'aición del Bardu Errante fala del xenocidiu

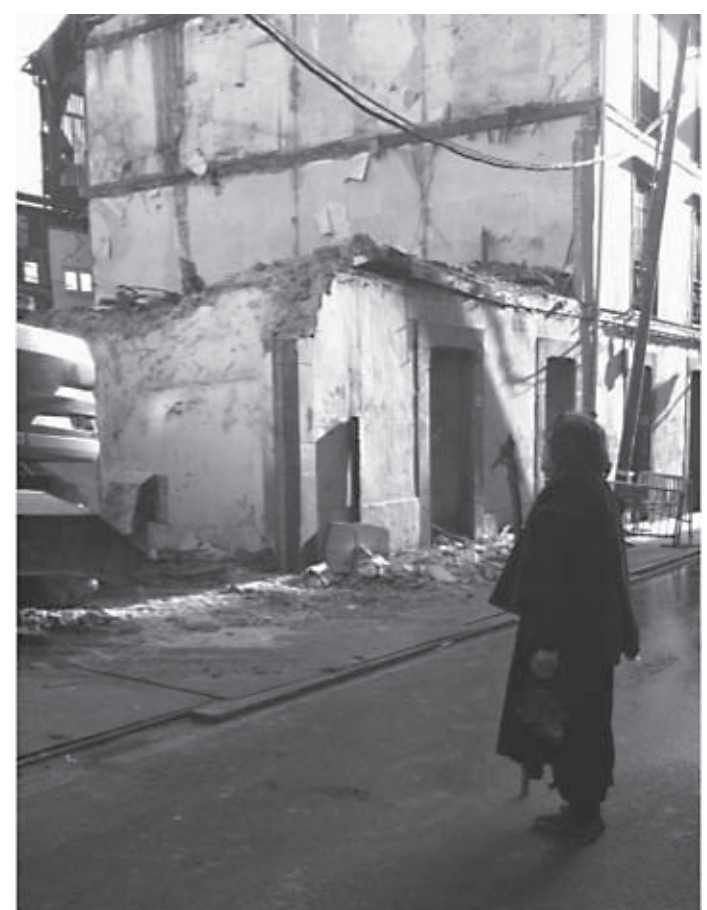

Fig. 3. En la parte superior: La piedra de la fortaleza será desierto, Adolfo Manzano, Instalación, Oviedo, 1999. Fuente: Archivo personal de Adolfo Manzano. En la parte inferior: A los héroes que fuimos, Adolfo Manzano, instalación, Plaza del Ayuntamiento de Pravia, 2007. Fuente: Archivo personal de Adolfo Manzano.

Ibidem.

71 FOUCAULT, Michel, "Des espaces autres", en Architecture, Mouvement, Continuité, $\mathrm{n}^{\circ}$ 5, octubre de 1984, pp. 46-49. 

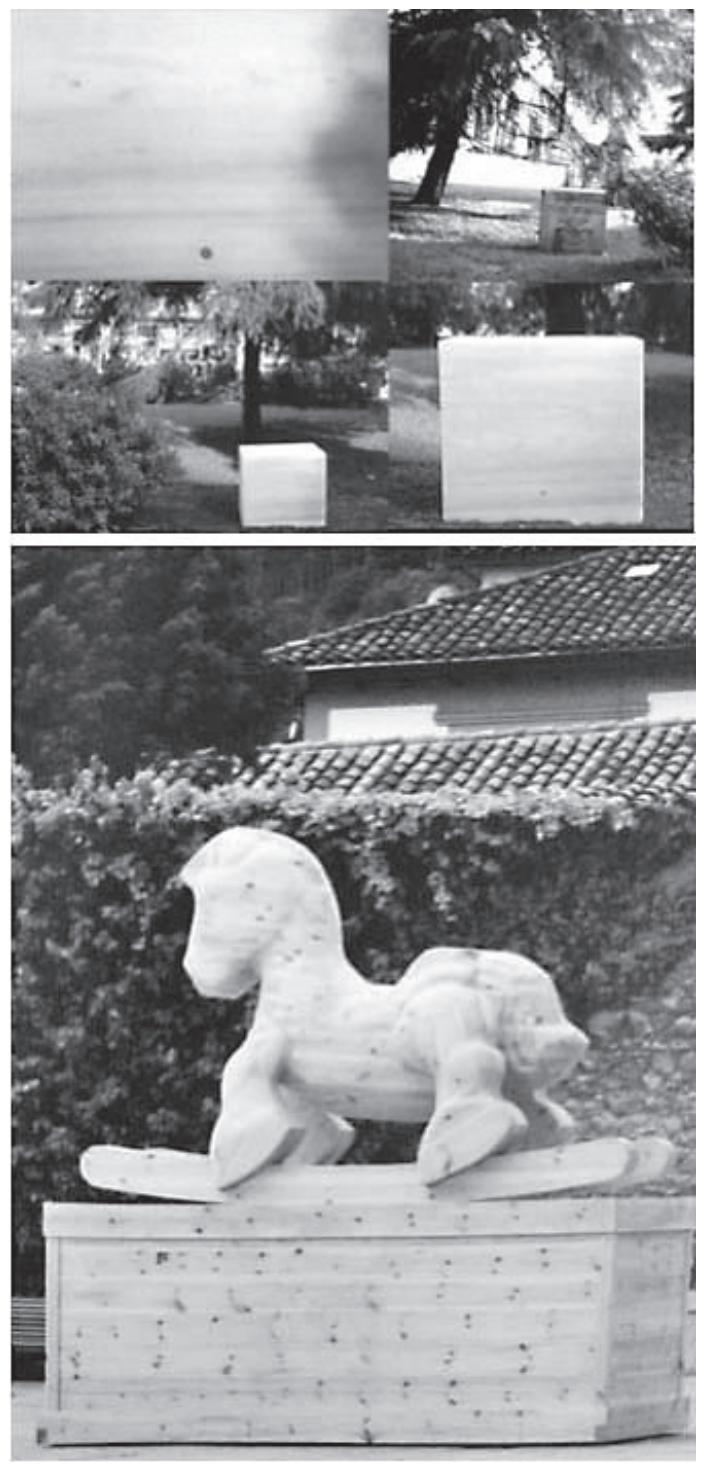

Fig. 4. Rapsodia de seronda, Ánxel Nava, performance y deriva urbana, Oviedo, 2013. Fuente: Archivo personal de Llorián García Flórez.

cultural d'un pueblu y la destruición, o idea peor, la usurpación de la so memoria» ${ }^{72}$. Las experiencias que ha llevado a cabo proponen que procesos que «atalanten espaciu y territoriu nel fenómenu de la recuperación y re-significación del llugar como espaciu vital. De la apropiación del territoriu como llugar a la mitopética de los llugares de la memoria hai una referencia al paisaxe, a la hestoria, a la cultural d'un país celta que mira tanto al pasáu como al futuru. Les visiones del territoriu propiu, llugares del

72 NAVA, Ánxel, "Memnonivm. Heterotopía de la memoria”. Catálogo de A: Campar, Consejería de Juventud y Festejos, Ayuntamiento de Gijón, Gijón, 2000. raigañu y la memoria, son finxos pa construyir el sentíu de la creación ${ }^{73}$.

Con ello, el punto de vista de Ánxel Nava se vincula con arquetipos comprendidos en tanto espacialidades en las que aparece sedimentado el pasado pero que, a la vez, desarrollan capacidades generadoras de afectos que actúan también en el presente. Profundiza, por lo tanto, en la imaginación expresada a través de lo simbólico pero llamando la atención hacia la máquina psíquica de cada cual; en la potencia de las capacidades imaginantes y de deseo. Invita al devenir, al contagio y a la afectación del público; es decir, «hacer experiencia con algo (...) significa que algo nos acerca, nos alcanza, que nos tumba y nos transforma ${ }^{74}$. De esta manera, como recogen sus palabras, el objetivo es «dar un aire más fondu que s'inxerte nel concimientu de la colectividá (...) que combata l'escaecimientu coleutivu mientres trabaya la memoria $^{75}$.

En el año 1986 aparecen perfiladas las anteriores cuestiones en el proyecto Muros de Ilión. Esta iniciativa trataba de crear espacios "míticos" interviniendo en los lugares o en los no-lugares de las urbes asturianas. La idea se basó en la intervención sobre los muros abandonados del Campu los Fresnos de la ciudad de Gijón. Para el artista esta ciudad es "un lugar escrito en lugar de otro lugar donde pierde su nombre mi ciudad» ${ }^{76}$. Así, de igual modo que planteó Constant décadas atrás, la ciudad parecía no estar en ruinas porque su ser se transformaba en habitable a través de la acción poética y creativa que trataba de generar "momentos vivenciales”. Es decir, estas obras sedimentaban lo efímero de los muros de la memoria, del sueño, de lo deslizante. La arqueología del sueño proponía la construcción de espacios comunes, simbólicos e identitarios que volvían a aportar actividad a los habitantes del lugar; siempre proponiendo un compromiso con una ética-estética huidiza y desterritorializada. En palabras de Natalia Tielve, "se levantaría como una suer-

\footnotetext{
$73 \quad$ NAVA, Ánxel, "Identidá y memoria nes artes d'Asturies (1985-2007)”. Catálogo de la exposición Identidá y memoria nes artes d'Asturies, FAC, 2007.

74 Ibidem.

75 DE LA TORRE GARCÍA, Antonio Alonso, "Dos ejemplos en Asturias de literatos reconvertidos en artistas de vanguardia”, en Correspondencia e integración de las artes Correspondencia e integración de las artes, $14^{\circ}$ Congreso Nacional de Historia del Arte, Málaga, Septiembre 2002, pp. 681-692.

76 Ibídem., p. 246.
} 
te de espejismo y de barricada ante la nada: el Topos como trampolín de acceso al Utopos» ${ }^{77}$. Por este hecho, utilizaba Nava la denominación "Arqueología del sueño" - «arqueoloxía porque l'artista escarba con muncha calma les llábanes pesaes del olvido, intentando averase al conocimientu de la propia memoria hestórica que ta enterrada na profundidá y suañu porque ye ilusión que caltién viva la utopía. Suañu que nagua por ser lexítimu des. u verde".lamentación"o "Etenáúisoarestiones en eléu de meyora pa una cultura que tien que saber que'l destín sí ta nes sos manes. Suañu maxín que contrasta con suapolis imaginarias (copiado) de resistencia ante el desierto de lo realna doble vertiene se muestran tambiso Sitios de inter las ñu lletargu, que ye'l que caltién dormíu al rebañu estacionáu nel tiempo l'escaezu» ${ }^{78}$. Ante tal situación, el creador rebautizaba los espacios en los que tenían lugar sus acciones como Tierra ensin nome -evidenciando la falta de memoria-, Tierra ocupada, Ciudad sitiada, Tierra de llamentación o Ermu verde. En definitiva, lo que ha planteado Ánxel Nava han sido "trincheras invisibles" en medio de paisajes urbanos deshumanizados que han quedado marcados, como no podía ser menos, por piedras ceremoniales o, como él mismo las denomina, piedres testimoniales. La figura del "agrimensor" ha sido la encargada de ocuparse de estas disposiciones y crear "rutas errantes para la memoria".

Desde final de la década de 1990 Ánxel Nava asume un posición novedosa que se definirá como un nuevo paradigma de acción: el bardu errante. De tal modo que, más pendiente de los procesos performáticos y performativos, Nava toma al Bardu como un comunicador poético. «Toi pa alliniar, apilar, arringlar les pallabres ensin qu'entornen nin caigan, nin tean atravesaes, pa que nun estorben sin que se ponga estorbises unes a otres ${ }^{79}$. De esta forma, ha recorrido el vacío de la Tierra erma para atravesar los desiertos que existen entre el arte, el espacio, la cultura y el pueblo. Así, una de sus máximas afırma que "la destruición de la memoria coleutiva, la función social del arte, exércela un Bardu errante que vien de la Tierra ensin Nome, que tien espoliada la obra y la casa llariega, pero caltién encesa la llama de

\footnotetext{
77 BARROSO, Julia y TIELVE, Natalia, Arte actual en Asturias...Op. Cit., p. 246.

78 Ibídem.

79 Ibídem.
}

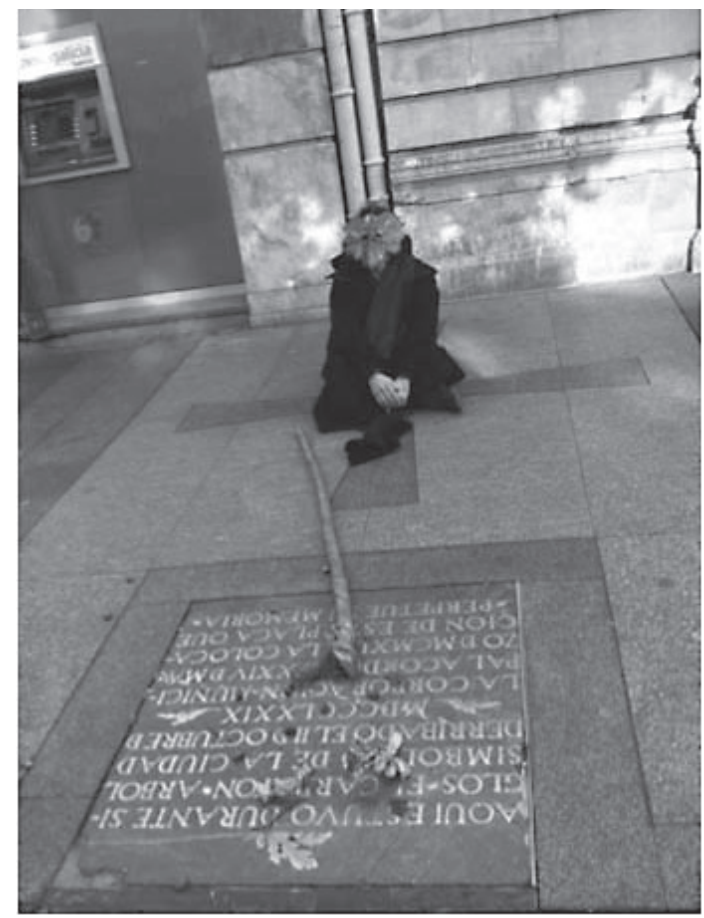

Fig. 5. Rapsodia de seronda, Ánxel Nava, performance y deriva urbana, Oviedo, 2013. Fuente: Archivo personal de Llorián García Flórez.

la llingua, que ye la memoria viva de la casa asturiana mentres quede'l caricós entá la llume caldia mentres que la nuesa casa la trabe encume celta nun anubre a fala la vieya memoria encesa entá la nuesa llingua caltién la llapa y na boca alluma'l fueu la pallabra» ${ }^{80}$.

\section{A modo de conclusión}

A lo largo de esta reflexión hemos tratado de comprobar cómo determinadas poéticas en el arte asturiano se han acercado de manera clave a cuestiones relacionadas con la memoria. Así, en un contexto que aún soporta diversas problemáticas inscritas en los espacios y las esferas públicas, el arte ha jugado un papel muy relevante como dinamizador. Ha tratado de articular nuevas memorias o, si se quiere, contra-memorias y, a su vez, ha elaborado resignificaciones que han señalado al recuerdo o al abandono, pero también a la memoria impuesta y al olvido obligado. El objetivo de estos artistas ha sido revisar un pasado reciente a fin de recuperar el olvido y fomentar perspectivas que no habían tenido suficiente presencia en la esfera pública: procesos de identidad, la lengua

$80 \quad$ Ibídem. 
asturiana, el abandono industrial, etc. Con ello, hemos tomado como casos de análisis diversos procesos que han tratado de trastocar diversas lógicas monumentales; esto es, no han perpetuado grandes gestas del pasado sino que han aludido a las huellas y han señalando a la monumentalización en tanto concepto múltiple. En tales perspectivas se han destacado y reelaborado elementos próximos a la memoria, también -y de manera más radical- los asociados al olvido: selección, exclusión, representación unidireccional, re-organización, etc. Por otro lado, este tipo de creadores se cuestionan la tradición del suelo que les ha visto nacer, de su lengua o de sus costumbres. El fin último no ha sido profundizar en el "origen de", sino más bien potenciar cómo la identidad se ha ido labrando en base a discontinuidades y heterogeneidades. En definitiva, han mostrado, no sólo la gloria pasada, también lo muerto, el silencio, la exclusión, la derrota o las ausencias; sobre todo porque han entendido, como apostilló Le Goff, la memoria como "un campo de fuegos cruzados y armas de poder ${ }^{81}$.

Todo ello se ha llevado a cabo desde prácticas que han tenido como principio la re-disposición de objetos e imágenes de un mundo común ya dado o "la creación de situaciones dirigidas a modificar nuestra mirada y nuestras actitudes con respecto al entorno colectivo» ${ }^{82}$. Avelino Sala, Adolfo Manzano y Ánxel Nava han sabido sugerir espacios comunes y relaciones que transforman el territorio común. Es decir, parece que han tenido claro que ante las situaciones de asedio y vacío se requiere un desplazamiento en la misma percepción en pos de desbloquear esferas particulares de experiencia, objetos sobre los que todos los actores tienen capacidad de hablar por ser comunes. Todo ello en busca de un "pretérito que relampaguea en el ahora de la cognoscibilidad es, con arreglo a su determinación ulterior, una imagen del recuerdo" ${ }^{83}$. En definitiva, arqueologías para el recuerdo, el sueño y la vida: "soñar espacios, invadir territorios vedados, tomar posesión del aire (...) La arquitectura escenográfica del sueño perdido es una arquitectura apuntalada. Arquitectura de lo existente y de lo desaparecido, que mantiene una cuña precaria entre el orden dominante y el orden otro, entre lo posible que nos imponen, y lo imposible que nos alejan (...) Todas las armas para ese combate. Mientras tanto, seguir afilando los dardos (...) Faigamos de la nuesa memoria, de les nueses alcordances, fuercies remocicaes ${ }^{84}$.
81 LE GOFF, Jacques, El orden de la memoria. El tiempo como imaginario, Paidós, Barcelona, 1991.
82 RANCIÈRE, Jacques, Sobre politicas estéticas, Museu d'Art Contemporani y Servei de Publicacions de la Universitat Autónoma, Barcelona, 2005, p. 15.

83 BENJAMIN, Walter, La dialéctica en suspenso. Fragmentos sobre la historia, Achis-Lom, Chile, 2000, p. 92.

${ }^{84}$ FORU ARTE CIUDÁ, "34 artistes, 14 díes de revolución”, Catálogo de la exposición Ochobre 34 artistes, 14 dies de Revolución, Mieres, Centro de Arte Casa Duró, 2004. 